\title{
CÂMBIO DE IDEIA: SOBRE DUAS GEOGRAFIAS POÉTICAS EXCÊNTRICAS
}

\author{
Jorge Wolff \\ (UFSC)
}

A experiência fundamental do escritor é a impotência. Com isto não pretendo distinguir entre escrever e estar vivo, mas apenas corrigir

a fantasia de que o trabalho criativo é um registro contínuo do triunfo da vontade, de que o escritor é alguém que tem a boa sorte de fazer aquilo que é capaz ou deseja fazer: imprimir, de forma segura e regular, seu ser numa folha de papel. Mas a escrita não é uma decantação da personalidade. E a maior parte dos escritores emprega boa parte de seu tempo em diversos tipos de tormento: querendo escrever, sendo incapazes de fazê-lo; querendo escrever de um modo diferente, sendo incapazes de fazê-lo. No tempo de uma vida são muitos os anos perdidos esperando a chegada de uma única ideia. $\mathrm{O}$ único exercício real de vontade é negativo: temos, em relação àquilo que escrevemos, direito de veto.

[...] Eu usei a palavra "escritor" deliberadamente. A palavra "poeta" deve ser usada com cuidado. É uma aspiração, não uma ocupação. Em outras palavras: não é um nome para um passaporte. 
Duas geografias poéticas bem distintas e igualmentevazias atravessam este trabalho. A ideia do câmbio ou da mudança de ideia parte de uma hibridação do espaço em que elas se pensam como impotência pura, num agora que já dura trinta ou quarenta anos: trata-se do "bleu portègne", nos termos do poeta Arnaldo Calveyra (1987), ou seja, da hibridação de Buenos Aires, Argentina, com Saint-Nazaire, França. Naturalmente que, em face dos escritores em questão aqui, nada é original e nem poderia ou pretenderia sê-lo, do câmbio de ideia, à epígrafe e aos poemas comentados: tudo é cópia, citação sem fim de outros poetas-escritores, escritores e poetas singulares e anônimos, estranhos e estrangeiros, embora não estranhos entre si. Vamos então aos nomes nas passagens e nos passaportes, para que os localizem e carimbem nessa aduana, e para finalmente esquecê-los ou vetá-los mais folgadamente. Há, portanto, um porto francês como primeira passagem, antigamente um assentamento celta chamado Corbilo e que a modernidade sob o disfarce iluminista do Oitocentos rebatizaria com o nome de um santo, Nazaire, Nazar, Nazário.

Um dos textos que um escritor nascido na cidade de Coronel Juan Pascal Pringles, no interior da Argentina - a outra dessas geografias assinou e datou no porto francês, em 1990, se chama El llanto. O outro se chamaria Nouvelles impressions du Petit Maroc, onde se lê, por exemplo, que "uma boa história escrita é sempre a 'história de um poema' antes que a dos fatos que conta" (AIRA, 1991, p. 14). Seu autor responde pelo nome de César Aira - ou "Hérat", conforme o pronunciam em França. O narrador de El llanto é um poeta que recebe uma bolsa para uma residência na Polônia (e não na França), onde chega, sem falar polonês, para uma temporada de um ano. Como não se faz entender na chegada, nem em polonês nem em nenhuma outra língua, torna-se rapidamente um indigente:

[...] tras quince días sin comer, dormir, cambiarme la ropa ni separarme un instante de mis dos pesadas valijas, me había transformado en una persona diferente de la que era en Buenos Aires. Mucho más que poeta, parecía un animal salvaje. (AIRA, 1991, p. 17)

Guardemos esta analogia entre o poeta e o animal selvagem e a imagem da hibridação. Na novelita de Aira, o poeta sobrevive ao inverno e às privações mais terríveis e finalmente consegue voltar aos braços de sua esposa em plena Argentina menemista (sendo Menem e Alfonsín nominalmente citados no texto), a qual, no entanto, imediatamente o troca por um certo japonês. Este se revela um terrorista que comete um atentado contra o primeiro-ministro argentino (embora a Argentina não seja uma república parlamentarista) e foge para o outro lado do mundo. 
Sua amante resolve se mudar para o Japão ao saber que será mãe de um filho do terrorista japonês e ao poeta-animal selvagem só resta cuidar do animalzinho - um cachorro - que criavam juntos num apartamento burguês da capital federal. O poeta trabalha como roteirista de uma famosa apresentadora de televisão, a qual, como não poderia deixar de ser, quer mudar de vida e se tornar uma estrela internacional de cinema. Em discussão com ela, no restaurante onde acontece o crime, apreciado por meio de uma parede de espelhos, revela-se a chave de toda a sua obra poética, ou seja, a ideia do "câmbio de ideia":

Mis poemas, siempre muy breves y elaborados, estaban marcados por la
torsión imperceptible de un "cambio de idea" en cierto punto de su desarrollo
fulgurante. Eso les daba una desarticulación característica, una extrañeza, y
hacía, creo, la esencia de su encanto: en una palabra, era mi estilo. (id.,., p. 23)

Para além do disparate e da burla, sensações gostosamente compartilhadas pelos leitores de Aira mundo afora, e do que o trecho pode significar para o seu próprio modo de narrar, baseado no "erro", esta chave não estaria longe da poesia de um escritor implicado com o argentino e a Argentina em mais de um sentido, o poeta francês, nascido em SaintNazaire em 1956, Christian Bouthemy, sobretudo no sentido de sua “estranheza” e "desarticulação característica”. Che cos’è la poesia? Entre outras coisas, escreve Jacques Derrida: "Não há poema sem acidente, não há poema que não se abra como uma ferida, mas que não fira também ele" (DERRIDA, 1992, p. 307). Nesta leitura de sua poesia, por razões que se esclarecerão em seguida, Bouthemy, além de errar e ferir à vontade, é o poeta que desapareceu - à maneira do narrador de El llanto - sem nunca ter deixado de publicar. Relendo Figures tombées traces (1983), o primeiro livro de Bouthemy, e tendo-o conhecido pessoalmente, em função da experiência que é o outro termo para viagem (como também escreveu Derrida), o poeta já tomava a frente em relação às suas atividades de editor e funcionário municipal. E isso de uma maneira tal que, apesar do autobiográfico e do memorioso mais prosaico, não cabe procurar traduzir senão através dos seus próprios poemas. Mesmo porque não apenas César Aira, em suas novas impressões de filiação rousseliana, mas também Alan Pauls na novelita Wasabi (escrita à época em Saint-Nazaire, onde

${ }^{1}$ El error es un detalle, y en realidad me encuentro en el mundo del detalle, es decir de la ficción. Eso lo sé con una perspicacia que comparte mis espacios interiores con el dolor, la fatiga, la inutilidad y el miedo a la muerte" (id., p. 12-13). Ideia que desenvolverá também em Nouvelles impressions du Petit Maroc através do conceito de "literatura mala". 
foi publicada em 1995, seguida de edição brasileira no ano seguinte), já o haviam transformado em personagem de ficção, baseados na experiência da residência de escritores fundada em 1986 sob o signo de Juan José Saer, seu "padrinho" - experiência esta em que Bouthemy, tendo idealizado e presidido então a Maison des Ecrivains et des Traducteurs (M.E.E.T.) de Saint-Nazaire, já aparecia entre os polos do poeta e do animal selvagem no que diz respeito à construção de seu próprio mito de jovem escritor rebelde e inconformista.

César Aira definia a sua cortesia, enquanto anfitrião de escritores e tradutores de várias partes do mundo, como "um tanto irônica"² e, na novela de Alan Pauls, ele figura com o nome de seu passaporte - isto é, seu nome real - desde o início até o fim, no itinerário do narrador que vai da residência na pequena cidade portuária na foz do rio Loire até os submundos da capital francesa, a ponto de protagonizar a conclusão do primeiro dos dois finais disponíveis. Ironia maior, em Paris Bouthemy não salva da miséria o narrador transformado em pária e tem a ousadia de chamar de impostor, aparentemente por desconhecer seu rosto envelhecido, o autor do próprio livro que editou em Saint-Nazaire - autor que é o próprio narrador de Wasabi, sendo esta mais uma história de escritor-protagonista ou, se quisermos, mais uma autoficção que, nesse caso, se antecipa à realidade, já que quem viria a se transformar em pária na vida real e em poucos anos seria o poeta e editor Christian Bouthemy, como se verá. Pois se trata do mesmo escritor que o editor tenta ajudar, ou melhor, "salvar" logo no início da narrativa, enviando-o ao consultório de sua homeopata preferida, como fazia com todos os hóspedes da MEET. Menos mal que a história da excrescência na nuca do escritor-narrador - tratada com a mostarda japonesa de nome wasabi3 receitada por sua amiga - tenha tido direito a um segundo final feliz.

Autoficção: em 1988, em visita a MEET, conheço o poeta e editor na França, em Saint-Nazaire. Em 1989 ou 90 revejo-o no sul do Brasil, de passagem por Florianópolis, quando o poeta e o animal selvagem já não se distinguiam e se divertiam, assim, indistintos "demoliendo hoteles" (para usar o nome da canção de outro artista selvagem, Charly García). Depois disso, o desaparecimento, o mergulho fundo nos subterrâneos,

${ }^{2}$ Aira também cita um poema seu no mesmo texto, sem referência (o que talvez signifique que o inventou e atribuiu a Bouthemy): "Je perds mon vocabulaire à chercher ma langue étrangère» ("Perco meu vocabulário em busca de minha língua estrangeira"). Em todo caso, há aí como que o anúncio de uma vontade de errar pelo mundo que se confirma integralmente num de seus últimos livros, Contours du souterrain (2008).

3 Nossa popular (hoje pop) "raiz forte". 
encarnando na realidade o papel atribuído ao editor em Wasabi: o de pária, o de drogado, o poeta e o animal selvagem definitivamente fundidos em uma criatura só. Quando finalmente em 2010 pude voltar a buscar o poeta, de quem nunca mais tinha tido notícias, foi que soube com surpresa da existência de Miette (1992), Filage (1994), Cosa mentale (1996), A quai, des printemps (2008) e Contours du souterrain (2008), todos breves coleções de poemas, com exceção do último. Este chama a atenção não apenas por ser o mais alentado e por não ter paginação ${ }^{4}$, mas também por apresentar poemas longos em uma série de registros de viagem a leste e a oeste da França, da Albânia (de onde vem a herança materna) ao Brasil (onde viria viver), compondo como que o seu itinerário subterrâneo durante a primeira década do milênio: 2001, bolsa de apoio à criação literária do Centro Nacional do Livro (como se lê na ficha técnica); abril de 2004 (em Nazaré [palavra que o persegue desde o berço], no Cabo de Santo Agostinho), data e local da primeira parte, "Pavés nordestins" - caderno de viagem pelo litoral do estado de Pernambuco; idem para "Itamaracá, Dhermi", título da terceira parte, com data de março de 2005 e março de 2007; e finalmente, para perturbar a linha do tempo, a quinta e última parte com data de 1994 e localização em Santa Cruz de la Sierra, na Bolívia, o poema "Descente de la rue Offenbach", significativamente dedicado a Juan José Saer.

Jovem poeta promissor, então com trinta anos de idade, Bouthemy foi o idealizador da Maison des Ecrivains Etrangers et des Traducteurs de Saint-Nazaire, à qual associaria o seu selo editorial, Arcane 17, a partir de 1986, quando a MEET foi inaugurada. A Arcane 17 fecha as portas em meados da década de 1990, paralelamente à destituição de Bouthemy à frente da MEET, quando se torna um viajante inveterado e demolidor (nos poemas há menções aos lugares mais inesperados e ao mesmo tempo mais esperados, em se tratando de um poeta selvagem), do qual os próprios submundos virtuais não podem dar mais do que escassa notícia. Já a MEET continuou em funcionamento ininterrupto desde então, seguindo o caminho das literaturas traduzidas e dos escritores-tradutores viajantes estrangeiros, imposto por ele sob o signo de Saer. O apartamento da MEET, num décimo andar diante do porto, é o cenário de vários relatos deixados pelos residentes de vários países, com preferência para escritores e tradutores de linhagem experimental. $\mathrm{O}$ espaço já foi esquadrinhado das mais variadas formas literárias e nas mais variadas línguas e povoa

${ }^{4}$ Como, aliás, todos os seus livros. Por este motivo, não são incluídos os números de página nas citações. 
grande parte dos relatos escritos no local, bem como certos habitantes da pequena cidade portuária. O escritor brasileiro Harry Laus, por exemplo, dedica a novela A primeira bala "à Bouthemy, assim como o fez Ricardo Piglia em Un encuentro en Saint-Nazaire (ambos publicados pela MEET/ Arcane 17 em 1989). Ocorre que a noção central em que se baseou a MEET na época de seu surgimento, a de "uma literatura sem qualidades" 5 , ou seja, de um anti-exotismo radical, é oriunda das posições estéticas de Juan José Saer, então professor de literatura hispano-americana na Universidade de Rennes, a capital da Bretanha localizada não longe de Saint-Nazaire. Poder-se-ia tomar a dedicatória do último poema de Contours $d u$ souterrain, "Descente da la rue Offenbach", em nome de Saer, como uma confirmação dessa afirmação. Tampouco parece ser mera coincidência que um dos primeiros convidados tenha sido Piglia, e que o tenham seguido os escritores Hugo Gola, Alan Pauls, Juan Carlos Mondragón e César Aira, entre outros rioplatenses ou platinos.

Passemos agora aos Contornos do subterrâneo, cujo sonoro título aponta para a trapaça com a própria biografia, com a própria experiência vital, vale dizer, em seu caso, com a própria experiência literária. Não é à toa que o poeta cita, no meio da suíte "Itamaracá, Dhermi", a frase de Alan Pauls (sem referência, traduzida aqui do francês): "Ler e caminhar são as duas faces de um mesmo vício: desenhar um percurso subjetivo, arbitrário e parcial, sobre uma superfície semeada de signos-página ou mapa que outros deixaram há muitos anos ou séculos". Desçamos caminhando, então, a rua Offenbach, para começar pelo final do livro, que remete ao lugar da infância. Desde o título, sabemos que se trata da memória, da fala e da música das ruas, seja na França, seja no Brasil - neste caso, nos "pavimentos nordestinos" da primeira suíte, em que, pela boca de Spinoza, se diz: "eu me agarro de preferência ... à Fala [à Parole]". Num dos grandes livros editados em Saint-Nazaire pela Arcane 17, L'art de raconter (El arte de narrar), Juan José Saer igualmente enunciava: "Nado/en un río incierto que dicen que me lleva del recuerdo a la voz". E logo no começo da descida da rua Offenbach, o poema, em sua dicção quebradiça, propõe uma noção significativa para o seu modo de escrever, a noção de "demi-mots" (ou meias-palavras), em que a sintaxe se quebra ainda mais, como que bêbada ou abolida. O primeiro movimento da "Descente" se chama "Mobile" e o segundo, "Dix mètres avant vingt mètres plus bas" («Dez metros antes de vinte metros abaixo»), mantém o movimento de sua poesia da (i) mobilidade e do não-senso, em que se lê: "J'écris gaucher, à l'endroit des

5 Título da primeira coleção de ensaios de Saer, publicada em 1985 pela Arcane 17. 
pages comme je m'inventai à gauche | le pavé trottoir à ne pas franchir, ce hors limite, dans cette intention | la verticalité du droit chemin de à chez moi » ("Escrevo esquerdo, no espaço das páginas como eu me inventava à esquerda | a pavimentada rua a não atravessar, este sem limite, nesta intenção | a verticalidade do caminho reto de à casa"). A desarticulação da sintaxe e do sentido é, neste caso, muito perceptível, ao contrário do poeta argentino de El llanto. Seguem as-os «Demi-mots» ("Meias-palavras"): «Encore bu un verre avant la ligne, ne sers rien juste | pouvoir sans buts, à cause être l'autre côté du trottoir non existant.| Pas le miroir, le concassé à venir.» («Ainda bebi uma taça antes da linha, não serve a nada justo | poder sem metas, por causa ser o outro lado da rua não existente. | Não o espelho, o triturado a vir."). E então as-os « Mots » ("Palavras") : «Ces vingt mètres ont chassé les dix mètres» («Estes vinte metros caçaram os dez metros»).

Estas palavras, apresentadas aqui em traduções preliminares, são quebradiças como a sua escrita em geral, são falas-palavras quebradas ao meio a partir de uma permanente tensão semântica, ora em forma do que chamamos poesia, ora em forma do que chamamos prosa, cujas descrições seriam as "únicas verdadeiras", ou seja, aquelas que - como disse o poeta italiano Giuseppe Conte - não se contentam com mostrar: "Uma verdadeira descrição deve revelar a parte invisível de todo objeto". ${ }^{6} \mathrm{O}$ que leva a pensar a descida daquela rua como ao próprio lugar da infância, ou seja, ao lugar da "não-palavra" e da "língua perdida": e já fazia tempo que Bouthemy - ouriço ferido - punha a perder seu vocabulário em busca de sua língua estrangeira, conforme César Aira. Mas logo depois, no começo da segunda e última parte, o poeta se soergue por um momento para observar, de modo cristalino, que: "Rue est différente de route. Rue est là où on s'arrête. Route vers là où on croit fuir" (" Rua é diferente de rota [estrada]. Rua é lá onde a gente se arrasta. Rota com destino fugitivo »). Ele cai, então, na estrada e isto a ponto de datar a sua descida à infância, mencionada antes, em 1994 na cidade boliviana de Santa Cruz de la Sierra, sendo que não há nenhuma referência à paisagem andina ou a qualquer outra paisagem além da própria "rua Offenbach". Finalmente, nos dois últimos versos do poema (e do livro), sua voz se divide não apenas no espaço mas também no tempo: "Nous ne sommes, moi et moi, du même temps. / Après tout ça, attendre; s’il suffisait du jour pour l'ombre” («Nós

${ }^{6}$ Leio o comentário no começo da entrevista de Giuseppe Conte - um dos primeiros escritores residentes da MEET - a Bernard Bretonnière, que conclui seu Manuscrit de Saint-Nazaire (MEET-Arcane 17, 1989). 
não somos, eu e eu, do mesmo tempo./Depois de tudo, esperar; se fosse suficiente o dia para a sombra»).

O poeta encara, assim, a sua rota, a sua estrada como a saída para o que não tem saída, o que remete a um poema de seu primeiro livro, que diz: "Chaque jour/la nuit revêt/son masque de vierge // La lumière frappe/l'angle du lieu / commun // Il est rarement minuit" ("A cada dia/ a noite veste/sua máscara de virgem // A luz bate/ no ângulo do lugar/ comum// Raramente é meia-noite"). E raramente é meio-dia porque, para Bouthemy, "as horas são desagregadas": volta-se aqui para o início dos Contornos do subterrâneo, aos "Pavés nordestins" (que se poderia traduzir como "pavimentos" ou "pedras" ou "ruas" nordestinas, isto é, de um certo Brasil). Assim, no início da primeira parte do livro, ele - alguém - diz, em tradução bárbara (como não poderia deixar de ser): "Eu gostaria que o leitor abordasse este livro, ou o sabotasse, vitória da liberdade, sabendo que as horas são desagregadas mas o ponto fixo" ("J'aimerais que le lecteur aborde ce livre, ou le saborde, victoire de la liberté, sachant que les heures sont désagregées mais le point fixe"). De modo que, após apontar o dedo ao leitor - que só poderá encontrar os livros desse "poeta raro" (na expressão de François Boddaert) em raras livrarias reais ou virtuais, a edição se limitando a trezentos exemplares -, surge a mencionada citação de Spinoza sobre a adesão desesperada do filósofo à "Parole". E a falapalavra leva ao mar, a pátria de adoção do poeta, sendo o primeiro poema um pedido de bênção a "Talassa".

O mar em questão é o pernambucano e desde o início aparece o tema da (i)mobilidade, da visão de uma paisagem fora do tempo, do ponto de vista do olhar do nativo: "Il est assis là depuis deux jours déjà / on dirait à califourchon sur le trou/qu'il doit combler. Le trottoir lui laisse/une place où poser son tas de cailloux/dont il travaille patiemment les formes / pour créer sa géométrie secrète» («Ele está sentado ali já faz dois dias/ como que a cavalo sobre o buraco/que ele deve preencher. A calçada lhe deixa / um lugar onde botar seu monte de pedrinhas / cujas formas ele trabalha pacientemente / para criar sua geometria secreta"). Sobre esse mar e sobre esse olhar "chove tanto que eu compreendo a deriva dos continentes» ("Il pleut tant que je comprends la dérive des continents"), conforme escreve no texto em que remete à 1912 e aproxima, como é de seu uso, o Cabo de Santo Agostinho ao golfo da Guiné, ou seja, o radicalmente excêntrico, além de anacrônico. Mas moi et moi, eu e eu estão diante do mar pernambucano, início do século XXI, e no poema seguinte, pelas televisões das ruas praieiras e repletas de gente do Recife, passam as torres gêmeas feridas, enfumaçadas e em queda livre, e o massacre de Karbala no Iraque: vida e morte, mobilidade e imobilidade, mudança sem ideia 
e ideia sem mudança. No poema em que o músico pernambucano Naná Vasconcelos é o seu observador fora do tempo - o décimo-primeiro de "Itamaracá, Dhermi" -, pode-se ler: "Nana Vasconcellos vient s'asseoir, et lui le percussioniste reste | immobile toute la matinée, sans même bouger les doigts, les yeux | rivés sur l'inexorable percussion des vagues vers leur fin" (Naná Vasconcelos vem se sentar, e ele o percussionista fica | imóvel toda a manhã, sem sequer mexer os dedos, os olhos | fixos sobre a inexorável percussão das vagas em seu fim"). Ao lado da recorrência desses temas, surge uma expressão que remete à noção de "demi-mots" e que, ao que tudo indica, amplifica as possibilidades de leitura de sua poesia: trata-se da noção de "visions émiettées", título de um poema dedicado ao balneário de Dhermi, na Albânia. Não por acaso, o segundo livro de Bouthemy se chamaria Miette ("Migalha"), de 1992.

Para concluir esta breve abordagem dos Contornos do subterrâneo (sequer mencionei a segunda suíte, "Szombathely-New York, Express"), cabe seguir direto ao seu elemento principal, ou seja, os próprios subterrâneos esmigalhados do mundo, através desse seu périplo de "homem de limiares", como o próprio poeta se define no final da suíte "Itamaracá, Dhermi": « Je suis un homme de lisières, les mots me sauvent en m'épuisant » ("Eu sou um homem de limiares, as palavras me salvam ao me esgotarem"). É a quarta parte desta suíte; na quinta, intitulada precisamente "Parois du souterrain" ("Paredes do subterrâneo"), as viagens à Albânia e Pernambuco, Europa do leste e América do sul, encontram-se na página do poema, cumprindo um destino comum, e incluindo uma graciosa licença poética em nome do som e do ritmo, em que o termo brasileiro "catadores" se castelhaniza para "cartoneros": « Ici en Albanie la même économie de dissections des déchets qu'à Recife./Là des cartoneros ici des canetteros ! passage du papier à l'aluminium. » (« Aqui na Albânia a mesma economia de dissecações dos dejetos de Recife./Lá os cartoneros aqui os canetteros ! passagem do papel ao alumínio").

Na segunda e última parte da mesma suíte, que leva a epígrafe de Alan Pauls sobre a relação entre ler e caminhar, chamada "Le souterrain mènerait à l'arbre à télévision" ("O subterrâneo levaria à árvore com televisão"), o tempo, o texto, o mar, a chuva, as árvores permanecem em questão (os poemas retomam sutilmente uns aos outros) e chega-se ao poema dedicado à imobilidade do percussionista. Da página imediatamente seguinte, destaca-se enfim a significativa profissão-de-fé às avessas ali apresentada, a propósito do Brasil, do Nordeste e de Recife: “... Je n'oserai parler | du Brésil, ou pour le moins du Nordeste, pas plus de Recife, et moins | encore de Boa Viagem, mais de ce quadrilatère dont je sais tous les | arbres et les caprices de leurs feuilles, tous les magasins et les heures 
| de relève des employés, l'heure des pluies, le retour des vents ...» (« Eu não ousaria falar | do Brasil, ou pelo menos do Nordeste, tampouco de Recife, e ainda | menos de Boa viagem, mas deste quadrilátero do qual eu sei todas as | árvores e os caprichos de suas folhas, todas as lojas e as horas | de troca dos empregados, a hora das chuvas, o retorno dos ventos...").

Para além dos juízos de valor, trata-se de um poeta e de uma poesia difícil de ser associada a qualquer outra, a qual procura enfatizar a seu modo "a parte invisível de todo objeto" (nos termos de Giuseppe Conte); que fornece, "pelo movimento, a ilusão do avanço" (como se lê no quarto poema da segunda parte de "Itamaraca, Dhermi"); que insiste na maneira como "sonham" as suas lembranças (sexto poema); que recusa a história e que define a vida - na suíte "Prova d'amore", que antecede a definitiva "Descida da rua Offenbach" - como "aquilo que nos escapa”, que se ausenta e esvazia, e que muda e muda novamente em toda sua imobilidade. E tudo isto para falar de poesia e de "parola" como impotência pura que se desdobra concretamente, no que diz respeito à intervenção deste escriba, em literaturas traduzidas, em (até o momento) dois livros de poesia publicados em agosto de 2011 e agosto de 2012, respectivamente: Figuras poentes traços (1983) e Ibura Séné - o qual foi lançado subterraneamente na França em maio último (após, portanto, o seu aparecimento no Brasil), ao lado de outra coleção de poemas recentes com título em português: Uma manhã sem favores, em versões impressas. Já Figuras poentes traços e Ibura Séné apareceram por aqui em forma de publicações eletrônicas que, como tais, também nos interrogam desde o papel em branco, sempre reciclável, reescrevível, embora com ares de eternidade, até a folha solta das galáxias virtuais como poesia singularmente fal(h)ada e espalhada mais do que nunca sem destinatário, vale dizer: bilhões de leitores = nenhum leitor.

Com Figures tombées traces (1983) o poeta de Saint-Nazaire estreava de maneira ainda "literária", no sentido de uma certa procura do sublime, de uma retórica pura e de uma poiesis (nos termos de Derrida), antes que seus poemas se esmigalhassem sem volta. Neles apresentam-se figuras, mas igualmente tombos, quedas, baques, poentes (conforme as opções buscadas para tombées), assim como traços riscados na carne das elegantes damas-da-noite da Bretanha, onde nasceu. Em Figuras, a explosão infraleve da primeira e mais longa seção do livro: começa o périplo do viajante sem porto, cujas horas já são então "desagregadas, mas o ponto fixo": o sem tempo em movimento e toda a imobilidade de aviões e navios. Nos cinco versos do primeiro poema (sem título, como todos), o corpo de um peregrino se movimenta na imobilidade do tempo e das coisas - leitmotiv do poeta em quarenta anos de pé na estrada. São línguas de fora, palavras 
balbuciadas em um cenário recendendo a um erotismo em claro-escuro, cuja pedra-umbral parece provocar o toque entre os objetos de um "teatro de águas". São, também, imagens refletidas na sonoite (a "tardinha”, o cedo da noite) que têm a finalidade explícita de não serem entendidas mas ouvidas: o escrever como desescrever, como não-saber. Afinal, trata-se com frequência da superposição de haicais baqueados cheios de imagens raras, estranhas que sussurram em primeiras pessoas vagas, ou cegas: eu descobri, eu enumerei, eu desenhei, eu procuro. Suas figuras sugerem naturezas mortas-vivas em busca do "gesto da chuva" que se dissolve lento, como o homem exaurido depois do auto-sacrifício: "O corpo divino será lavado / na água da cheia”. Tudo é sonho e entressonho, precisamente como, muito mais tarde, o fará nos "Pavimentos nordestinos", no início dos Contornos do subterrâneo, cuja primeira epígrafe diz: "Não sou mais que um sonhador e não tenho mais que um desejo / dizer o que eu sonho" (Germain Nouveau). Vale evocar, ainda, a segunda epígrafe do livrofuturo, uma vez que dá conta da vida das palavras nessa poesia traçada a água e fogo: "As palavras morrem de esgotamento" (Robert Walser). Obviamente os descaminhos bretões não são ainda os nordestinos, a lembrança do futuro se faz em função de uma coerência - talvez a única - entre poesia vivida e vida sonhada. Ao contrário dos últimos, mais narrativos, os primeiros poemas são na maioria diamantinos, breves, concisos ao extremo, contrastando na página branca noite e dia, o tempo e o espaço, a mobilidade e a imobilidade, em imagens surreais.

Figuras de reis negros e relógios mortos: tudo é perfeitamente intraduzível no reino em que, como se viu, "raramente é meia-noite": "a cada dia / a noite veste / sua máscara de virgem”. Enumeram-se certas figuras recorrentes na literatura, mas sob a forma de gato e de cisne esquivos; quanto às águas, ganham o poder de penetrar a dor; e estrela nascente se imobiliza, por sua vez, à espera da hora em que "a página se ausenta”. O mar, os frutos do mar, o vento e os frutos do vento: instantâneos das coisas da natureza, a voz dos grãos de areia (alimento para os livros que vão vindo), em que se poderia verificar talvez um rastro pongiano.

Em Poentes, a segunda parte deste livro menor, há três poemas em prosa. O primeiro pareceretomar (ainda umavez) o futuroatravés da relação entre caminhar e escrever, além da resignação diante do apelo - como "uma falésia saliente" - do vazio. No segundo poema, uma vaga inquieta sacode a imobilidade, no "voo rasgado de uma gaivota", que "atravessa a infinita dor de um dia que se apazigua": tombos, baques, sonoites, poentes. No terceiro, celebra-se a "aurora de uma memória abolida", vale dizer: não saber, sonhar, esquecer-lembrar. Já em Traços lê-se que da landa viemos e à landa voltaremos, pois chove no deserto desolado da terra. Quanto ao 
corpo, “ocre e doce”, é pura sensação: corpo feminino, “ocre se escreve no oco dos rios", onde se reflete sempre outra lua, sempre outro sonho. Pois e com essa frase se fecha o livro de estreia de Bouthemy - "não há realidade além dessa palavra" (Ribemont Dessaignes) ${ }^{7}$. É o começo das viagens do poeta mundo afora. Outras viagens, vale dizer, outros livros virão. Cada vez mais viageiros e deliciosamente intraduzíveis. A esse propósito (a propósito desta e das traduções por vir), limito-me a transcrever um poema de Filage, publicado por Bouthemy, aqui mais que nunca o poeta das literaturas traduzidas, em 1994: "A tradução não passa da passagem do sagrado ao profano. Que se atente ao que esse termo anuncia”.

Ibura Séné, um de seus últimos livros, traz embutido desde o título uma questão: como conciliar estas duas palavras inconciliáveis senão através da voz e do nome do poeta perdido? Não há ponto de partida nem de chegada: se Figuras Poentes Traços abre um modo de escreviver, os poemas de Ibura-Séné fazem e refazem o mesmo gesto diferido na poeira e na lama das distâncias. Longas distâncias percorridas no decurso de uma vida sem bios: Je n'existe pas seria o epíteto apropriado para Christian Bouthemy (nascido em 1956), o poeta que desapareceu - lembremos - sem nunca ter deixado de publicar. Não seria possível fornecer pistas para um leitor ideal desses poemas mas, antes, migalhas delas: a vida e a morte na e sobre a estrada. Na estrada porque o que se lê neste livro, assim como nos demais da safra XXI, são rastros de viagens, viagens móveis e também imóveis, para dentro e para fora de si mesmo, com e sem direção. Sobre a estrada porque este foi, literalmente, o ponto de vista do poeta em sua casamata pernambucana: pendurado na favela sobre uma auto-estrada, toda "a dor dos motores / dos caminhões transbrasileiros”. Ibura, comunidade pobre de Recife, com o mais baixo IDH da capital de Pernambuco, onde o poeta vive quando está no Brasil. Península Séné, na Bretanha francesa, região rica em vestígios celtas e abrigo do poeta durante oito meses de 2001, em um hospital para recuperação de dependentes químicos. Da conjunção dessas experiências dos limites nasceram esses poemas, disparados no entanto pela primeira viagem de Bouthemy, aos 16 anos, a Szeged, na Hungria dos anos de chumbo.

À diferença dos primeiros livros, as últimos coleções de poemas (publicadas ou por publicar), ainda que guardem em toda sua potência o non-sense característico do poeta, apresentam-se mais prosaicos, narram pedaços de histórias em paisagens e atmosferas invariavelmente tensas

7 Trata-se de um procedimento frequente em seus poemas, o de pospor citações de diversos escritores imediatamente após o fim do poema. 
e concentradas. A melancolia, mas igualmente a violência embutida em todas as coisas. Mais que a vontade de viver ou morrer, o desejo de viajar. A força das torções sintáticas em nome do amor livre, "em que outra paragem? que outro antro?". A magia dos registros vulgares e os tons de azul que os negam. A voz grave capaz de secar as conchas em Séné: caminhar significa ler e vice-versa. Os cinzas da cor do cisco nos olhos, capazes de abrir um corpo para o outro. O rumor e o embrulho das línguas em brasas e cinzas. A confiança cega nos poderes do esquecimento. A Hungria, mas também a Geórgia: em Tbilissi, toda a vertigem de "uma estrela soletrando as outras". O frio e o calor mais duros, sem meio termo. O branco das neves, o preto dos pneus sobre um solo escondido. Todo o silêncio impossível de dentro e de fora das coisas. Um olhar diário sobre a violência e a velocidade. A sinopse de um dia que se extingue pela vida inteira. Os prazeres e movimentos do álcool e do sexo, não fazendo nada, absolutamente nada "por medo de que seja tarde demais". Os ruídos da música e do cinema mudos em relevo. O sol - "branco de necessidade" - e a água - invisível, segura. Os usos e o ouzo do nordeste: pitu. As vitórias e as possessões por amor à farsa do amor das mulheres. A ida e a volta sem volta da desesperança, em Szeged, Tbilissi, Saint-Nazaire, Recife ou Montevidéu, conciliando o inconciliável, como nos títulos das suítes dos Contours du souterrain, em que as geografias mais diversas se encontram de maneira inusitada: Ibura-Séné.

Para terminar, evoquemos uma questão mais delicada: a questão do poema dos nossos sonhos ainda demasiado literários em tensão com aquela dos sonhos sinistros de nosso ouriço para sempre inapreensível. É talvez preciso reconhecer ou supor que Christian Bouthemy, que remexe na terra sequioso para escrever sem exercer, contudo (como diria a poeta americana Louise Glück), qualquer poder de veto, transita entre a "mala literatura" e a "literatura mala" (para usar a expressão de Aira em Nouvelles impressions du Petit Maroc). E que seu tradutor (mau, malo, maldoso, maldoroso?) transita, por sua vez, antes que pelo esquema da transcriação, pela cama antiesquemática da literalidade, com base em um fardo autobiográfico. É preciso reconhecer ou supor também, por outro lado, que a experiência em curso de tradução dos Contornos do subterrâneo ruma lentamente, pacientemente da literalidade semântica bruta ou selvagem para um mais decidido mergulho no poema enquanto som em detrimento do sentido, posto que, como se sabe, as letras cantam diversamente em cada língua. Não que a hesitação se conclua, sendo esta a própria impossibilidade possível da poesia, mas sim que balance perigosamente em direção à música pura ou ao ritmo impuro do poeta que de início apenas ciciava ou murmurava em breves poemas de 
filiação surrealista e que passa a uivar e a urrar como um animal selvagem acuado. Este vago animal, "ese vago durmiente - como escreveu o poeta Arturo Carrera - arrastrado por una autobiografía irreprochable por desconocida" (CARRERA, 2009, p. 152-3).

\section{REFERÊNCIAS BIBLIOGRÁFICAS}

AIRA, César. Nouvelles impressions du Petit Maroc. Saint-Nazaire: MEET/Arcane 17, 1991. [Ed. bras. Florianópolis: Cultura e Barbárie, 2012, trad. J. Wolff]. . El llanto. Rosario: Beatriz Viterbo: 1992.

BOUTHEMY, Christian. Figures tombées traces. Saint-Nazaire: Arcane 17, 1983 [Ed. bras. on-line em Sopro 57, Florianópolis, agosto 2011, trad. J. Wolff].

. Ibura Séné. Paris: Par-delà les mythes éditeur, 2013 [Ed. bras. on-line em Sopro 75, Florianópolis, agosto 2012, trad. J. Wolff].

. Contours du souterrain. Paris: Par delà les mythes éditeur/Obsidiane, 2008.

. Filage. Saint-Nazaire: Arcane 17, 1994.

. Miette. Saint-Nazaire: Arcane 17, 1992.

. Cosa mentale. Saint-Nazaire: MEET, 1996.

. À quai, des printemps. Paris: Par delà les mythes éditeur, 2008.

. Uma manhã sem favores. Paris: Par delà les mythes éditeur/Obsidiane, 2013.

C ALVEYRA, Arnaldo (texto); GORNEG, Paol (fotografia). Bleu portègne. Soixante-douze photographies pour un alphabet de Saint-Nazaire. Saint-Nazaire: Arcane 17, 1987.

CARRERA, Arturo. Ensayos murmurados. Buenos Aires: Mansalva, 2009.

CONTE, Giuseppe. Manuscrit de Saint-Nazaire. Saint-Nazaire: MEET-Arcane 17, 1989.

DERRIDA, Jacques. Che cos'è la poesia? In: Points de suspension. Paris: Gallimard, 1992.

GLÜCK, Louise. Education of the poet. In: Proofs E theories. Essays on poetry. New York: Ecco, 1994.

PAULS, Alan. Wasabi. Saint-Nazaire: MEET-Arcane 17, 1995.

SAER, Juan José. L'art de raconter. Tome 1. Poèmes 1960/1975. Traduit par Laure Bataillon. Saint-Nazaire: Arcane 17, 1990.

. Une littérature sans qualités. Saint-Nazaire: Arcane 17, 1985. 